УДК 616.125-008.313.2-08

\title{
Батушкин В. В.
}

Информация об авторе:

Киевский медицинский университет УАНМ, г. Киев, Украина Киевская городская клиническая больница № 5, г. Киев, Украина

Резюме. В 2016 году в Киевской городской клинической больнице № 5 проведено лечение 591 больному, госпитализированному с острым инсультом, из них -482 (81,6\%) с ишемическим, 109 (18,4 \%) с геморрагическим. В процессе лечения 114 (19,3\%) больных умерло в стационаре. Характерно, что госпитальная смертность от геморрагического инсульта была более чем в 2 раза выше, чем при ишемической природе последнего (36,7 \% и 15,4 \% соответственно). Самыми частыми предикторами летального инсульта являлись фрибрилляция предсердий и артериальная гипертензия. Согласно последним рекомендациям Европейского общества кардиологов (2016), скрининг фрибрилляции предсердий основан на клинических проявлениях, продолжительности и возможности спонтанного прекращения серии эпизодов аритмии. Просрилактика инсульта у пациентов с фрибрилляцией предсердий заключается совсем не в рациональной антиаритмической терапии. Назначение пероральных антикоагулянтов может предотвратить большинство ишемических инсультов у пациентов с фибрилляцией предсердий и продлить жизнь. Это доказано в исследованиях, в которых участвовало большое количество больных - антикоагулянты превосходят по выживаемости плацебо или аспирин у пациентов с различными профилями риска инсульта. Явные положительные клинические результаты носят почти всеобщий характер, за исключением пациентов очень низкого риска инсульта, и поэтому современные пероральные антикоагулянты следует использовать у большинства пациентов с фрибрилляцией предсердий.

Ключевые слова: фрибрилляция предсердий, тромбоэмболические осложнения, 
инсульты, профилактика, пероральные антикоагулянты.

Фибрилляция предсердий (ФП) является наиболее распространенной аритмией сердца и причиной трети госпитализаций, связанных с нарушениями сердечного ритма. ФП развивается примерно у одного из четырех человек в возрасте 55 лет с немного большей частотой возникновения у мужчин, чем у женщин (24\% по сравнению с $22 \%$ соответственно) [1, 2]. У 20-30 \% пациентов, перенесших ишемический инсульт, диагностируется ФП (до, после либо во время инсульта).

Ишемический инсульт не только чаще всего случается у пациентов с ФП, но и обычно является более тяжелым, чем инсульты, вызванные другими причинами [1]. У 80 \% пациентов с ФП с высоким риском первый ишемический инсульт, скорее всего, смертельный или вызывает временную инвалидность [3].

В 2016 году в Киевской городской клинической больнице (КГКБ) № 5 проведено лечение 591 больному, госпитализированному с острым инсультом, из них - $482(81,6 \%)$ с ишемическим, 109 (18,4 \%) с геморрагическим. В процессе лечения 114 (19,3 \%) больных умерло в стационаре. Характерно, что госпитальная смертность от геморрагического инсульта была более чем в 2 раза выше, чем при ишемической природе последнего $(36,7$ $\%$ и $15,4 \%$ соответственно).

Распространенность фракторов риска среди выживших и умерших представлена в таблице 1.

Таблица 1. Факторы риска смерти у больных с острым инсультом на госпитальном этапе (по материалам КГКБ $\square$ 5)

\begin{tabular}{|c|c|}
\hline पФакторы риска & (Ишемический инсульт \\
\hline$(n=482)$ & (Геморрагический инсульт \\
\hline$(n=109)$ & \\
\hline
\end{tabular}




\begin{tabular}{|c|c|c|c|}
\hline पВыжившие & $\square$ Умершие & पВыжившие & $\square$ Умершие \\
\hline$\square(n=408)$ & $\square(\mathbf{n}=74)$ & $\square(\mathbf{n}=69)$ & $\square(\mathbf{n}=\mathbf{4 0})$ \\
\hline \multicolumn{2}{|c|}{ 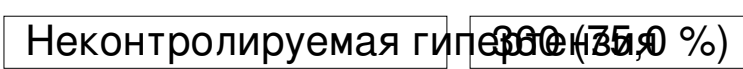 } & $68(91,9 \%)$ & $47(68,1 \%)$ \\
\hline \multicolumn{2}{|c|}{ Фибрилляция предсердИн4 (35,3%) } & $70(94,6 \%)$ & $21(30,4 \%)$ \\
\hline Гиперкоагуляция & $194(47,5 \%)$ & $56(75,7 \%)$ & $20(29,0 \%)$ \\
\hline Дислипидемия & $200(49,0 \%)$ & $69(93,2 \%)$ & $41(59,4 \%)$ \\
\hline \multicolumn{2}{|c|}{ Отягощенный анамнез 132 (32,3 \%) } & $63(85,1 \%)$ & $39(56,5 \%)$ \\
\hline
\end{tabular}

Согласно показателям таблицы, самыми частыми предикторами летального инсульта являлись фрибрилляция предсердий и артериальная гипертензия (АГ).

Диагностика ФП относительно проста и заключается в регистрации ритма сердца с помощью электрокардиограммы (ЭКГ). Типичная картина ФП характеризуется абсолютно нерегулярными интервалами R-R и отчетливо неразличимыми P-волнами. По общепринятому мнению, эпизод аритмии, продолжающийся 30 секунд и более, является диагностически значимым. Вместе с тем ФП может быть симптомной и бессимптомной. У большинства пациентов наблюдается оба клинических варианта аритмии.

«Молчаливая» («silent»), бессимптомная ФП, как правило, характеризуется тяжелыми последствиями, такими как инсульт и смерть. Обычная запись ЭКГ является эфрфрективным и экономичным методом для диагностики, в основном хронических фрорм ФП. Технология для обнаружения пароксизмальной, самостоятельно прерывающейся ФП продолжает стремительно развиваться. 
Существуют убедительные доказательства того, что длительный (более 24 часов) ЭКГ-анализ значительно улучшает обнаружение скрытой ФП. Рекомендуется, например, мониторинг в течение 72 часов или даже дольше. Обычные краткосрочные записи ЭКГ, проводящиеся ежедневно, увеличивают шансы обнаружения пароксизмальной ФП среди лиц старше 75 лет. Текущее наблюдение дает шанс раннего обнаружения, что изменяет терапию (например, начало антикоагуляции), и улучшает исходы, особенно после инсульта [4].

После ЭКГ-диагностики ФП дальнейший ЭКГ-мониторинг позволяет отслеживать:

1) динамику симптомов или появление новых симптомов;

2) предполагаемое прогрессирование ФП;

3) оценку воздействия препарата на желудочковый ритм;

4) эфрфект антиаритмических препаратов или катетерной абляции на сердечный ритм.

Скрининг «молчаливой» ФП предполагает несколько мероприятий. В клинической практике - это, прежде всего, регистрация фрибрилляции предсердий по ЭКГ. Невыявленная ФП - распространенное явление, особенно среди пожилого населения и больных с сердечной недостаточностью $(\mathrm{CH})$. Традиционный скрининг бессимптомной ФП является экономически выгодным среди пожилого населения (старше 65 лет), и подобные результаты были оценены с помощью многоканальной ЭКГ при скрининге в группах риска. Систематическое обследование пожилого населения (средний возраст 64 года) выявило распространенность хронических фрорм ФП у 2,3 \% среди 122571 обследуемых, для которого использовалась одномоментная ЭКГ или пальпация пульса (а затем ЭКГ у лиц с неритмичным пульсом) [1, 3, 4]. Ранее недиагностированная ФП была выявлена у 1,4 \% лиц старше 65 лет.

Длительное наблюдение за пароксизмальной фрормой ФП крайне важно. О ней и врачи, и пациенты часто забывают. Повторные ежедневные записи ЭКГ увеличивают шанс 
обнаружения бессимптомной пароксизмальной ФП в широких слоях населения, особенно среди пациентов старше 75 лет. Существует несколько автоматических устройств для непрерывного мониторинга ЭКГ. Чаще всего используются различные навесные записывающие аппараты. Преимущества в обнаружении бессимптомной ФП с помощью новых технологий, таких как смартфоны с ЭКГ-электродами, «умные» часы и аппараты для измерения артериального давления с алгоритмами обнаружения ФП, еще недостаточно глубоко оценены по сравнению с традиционными методами обнаружения аритмий.

Из 591 пациента с инсультом, проходивших лечение в КГКБ № 5 в 2016 году, у 232 (39,3 \%) больных отмечались различные фрормы ФП. Причем только у половины из них (56,0 \%) наблюдалась перманентная фрорма, среди остальных: у 60 (25,8 \%) больных персистентная, а у 42 (18,2\%) - пароксизмальная.

Обнаружение ФП у перенесших инсульт особенно важно. Sposato L. A., Cipriano L. E., Saposnik G. (2015) провели целевой мониторинг ЭКГ и обнаружили ФП у 24 \% пациентов, выживших после инсульта. В другом исследовании Kishore A., Vail A., Majid A. (2014) выявили ФП у 11,5 \% пациентов. Это свидетельствует о том, что существуют большие вариации распространенности ФП в зависимости от сроков, продолжительности и методов мониторинга [3, 4].

Встречаемость ФП не является редкостью и в общей популяции больных - 6,2 \% с большим удельным весом среди больных с криптогенным инсультом при условии использования имплантированных записывающих устройств ЭКГ при мониторинге в течение нескольких недель.

Криптогенный инсульт определяется как инсульт, при котором причины не могут быть определены даже после тщательного стационарного обследования. Более широкое определение имеет эмболический инсульт без неопределенного источника.

Несколько исследований выявили ФП у пациентов, у которых была другая конкурирующая причина инсульта (например, АГ или стеноз сонной артерии). Таким образом, длительный мониторинг ЭКГ представляется необходимым для всех выживших после ишемического инсульта без установленного диагноза ФП. 
Согласно последним рекомендациям Европейского общества кардиологов (The European Society of Cardiology, ESC) 2016 [4], скрининг ФП основан на клинических проявлениях, продолжительности и возможности спонтанного прекращения серии эпизодов ФП:

- внеплановый скрининг с целью выявления ФП показан пациентам старше 65 лет (путем контроля пульса или регистрации ЭКГ покоя) (класс рекомендаций I, уровень доказательности В);

- систематический скрининг с контролем ЭКГ для выявления ФП показан всем пациентам старше 75 лет либо лицам с высоким риском инсульта (класс lla B);

- пациентам, перенесшим инсульт или транзиторную ишемическую атаку (ТИА), для выявления ФП показана регистрация ЭКГ покоя с последующим мониторингом ЭКГ как минимум в течение 72 часов (класс I В);

- пациентам, перенесшим инсульт, показан дополнительный длительный мониторинг ЭКГ (в том числе с имплантацией петлевых регистраторов ЭКГ) для выявления возможной бессимптомной ФП (класс Ila B).

Традиционно выделяют пять видов ФП: впервые установленная форма аритмии, пароксизмальная, персистирующая, давняя стойкая персистирующая или постоянная ФП. Если пациенты одновременно имеют эпизоды и пароксизмальной, и персистирующей ФП, следует использовать для классифрикации более общий тип. Очень часто клинические критерии ФП не соответствуют данным, полученным путем долгосрочного мониторинга ЭКГ. Еще меньше известно о реакции на терапию больных с давней стойкой персистирующей ФП или давней пароксизмальной ФП. Несмотря на эти неточности, различия между пароксизмальной и персистирующей ФП используются в проведении многих клинических исследований и поэтому по-прежнему составляют основу современных рекомендаций.

Риск развития ФП увеличивается при различных фризиологических состояниях и болезнях, и исторический термин «изолированная ФП», вероятно, вводит в заблуждение, поэтому его следует избегать. Хотя модель ФП может быть похожей, механизмы, лежащие в основе аритмии, у пациентов существенно отличаются. Это 
говорит о том, что нужно стратифицировать пациентов с ФП, указывая движущие причины (драйверы) аритмии с разграничением болезней сердца и системных сопутствующих заболеваний (например, сахарный диабет и ожирение), фракторов образа жизни (например, уровень фризической активности, курение, употребление алкоголя), маркеров сердечного ремоделирования (например, фриброз или составляющие электрокардиографические параметры ФП) и генетического фона.

В последние годы внимание кардиологов привлекает способность детекции «молчаливой» ФП у пациентов с имплантированными электрокардиостимуляторами (ЭКС) или дефибрилляторами. Наличие предсердного электрода позволяет контролировать ритм предсердий путем длительных записей. С помощью этой технологии можно идентисрицировать пациентов с эпизодами предсердной тахикардии либо эпизодами сокращений предсердий высокой частоты («atrial high rate episodes», ЭСПВЧ). В зависимости от группы риска такие ЭСПВЧ обнаружены у 10-15 \% больных с кардиостимуляторами. Они связаны с 5,56-кратным повышенным риском явной ФП. Безусловно, наличие таких эпизодов ассоциируется со значительно большей частотой ишемического инсульта или системной эмболии (в 2,56 раза). При этом частота инсульта у пациентов с ЭСПВЧ несколько ниже, чем у больных с подтвержденной ФП, поскольку последняя выявляется не у всех таких пациентов. Показана ли антитромботическая терапия пациентам с ЭСПВЧ - вопрос, исследующийся в настоящий момент в рамках двух клинических испытаний (ARTESiA и NOAH - AFNET 6). В настоящий момент рекомендовано контролировать частоту работы предсердий у пациентов с имплантированными кардиостимуляторами или дефибрилляторами, а в случае выявления эпизодов сокращений предсердий высокой частоты дополнительно обследовать их с целью выявления ФП, а также оценивать риск ишемических осложнений (рисунок 1).

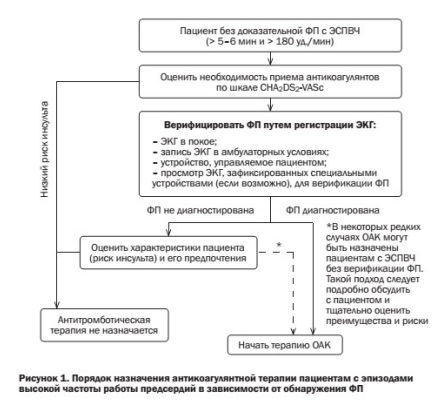

У пациентов с имплантированными ЭКС или кардиовертерами следует регулярно оценивать частоту работы предсердий. В случае выявления эпизодов высокой частоты работы предсердий необходимо дополнительное обследование (мониторинг ЭКГ) для 
верифрикации ФП и назначения соот ветствующего лечения (класс I В).

В рекомендациях ESC 2016 года разработаны элементы комплексного наблюдения за лечением ФП на амбулаторном этапе (таблица 2). В ряде опубликованных научных работ показано, что комплексный подход по срав нению с обычным уменьшает примерно на треть количество госпитализа ции и сердечно-сосудистой смерти при наблюдении в течение 22 месяцев (14,3 \% против 20,8 \%; относительный риск 0,65; 95 \% доверительный ин тервал (ДИ) 0,45-0,93; представляет ся и экономически более выгодным [1].

\section{Таблица 2. Компоненты комплексного наблюдения и лечения ФП на современном этапе}

\section{Рекомендация}

\section{$\square$ Класс рекомендации Уровень доказательности}

Рекомендации по применению комплексного подхода в терапии

Следует рассмотреть цевесообразность примеВения комплексного подхода со структурной о Главную роль в принятиlарешения следует отвСдить мнению пациента с целью адаптации те Рекомендации по обследованию пациентов с ФП

Регистрация ЭКГ необхбдима для верификациВ диагноза ФП

Рекомендуется полное фбследование сердечноєсосудистой системы, включая скрупулезный а Всем пациентам с ФП пьказано проведение трфнторакальной эхокардиографии для коррекь Следует рассмотреть цевесообразность провећения длительного мониторинга ЭКГ у отдель Рекомендации по оценке риска инсульта и кровотечения

Рекомендуется использьвать шкалу CHA2DS2- גASc для оценки риска инсульта у пациентов Следует оценить риск крњвотечения у пациентњ с ФП, принимающих ОАК, для выявления мс Биомаркеры (высокочувыфы вительный тропонин В натрийуретический пептид) можно использо

Большинству пациентов с ФП необходимо регулярное наблюдение для обеспечения дальнейшего оптимального лечения. Последующие наблюдение и лечение осуществляют в порядке медицинской помощи специально обученные медсестры, кардиологи либо аритмологи. Специалист должен координировать помощь и последующие мероприятия. Комплексное на блюдение обеспечивает контроль плана лечения, комплаенс пациента и адаптацию терапии к течению болезни. 
Оценка клинического риска инсульта и системной эмболии занимает очень важное место в рекомендациях 2016 года.

Простые клинически применимые схемы стратификации риска инсульта у пациентов с ФП были разработаны еще в конце 1990-х в небольших когортных исследованиях и позднее были уточнены и проверены на больших популяциях пациентов.

Таблица 3. Шкала расчета риска развития инсульта, транзиторной ишемической атаки, системной эмболии

\section{Фактор риска CHA2DSEaHAisc}

Хроническая сердечная недостаточность (CH)

Клинические признаки GH или объективные доказательства снижения фрракции выброса (ФВ)

\section{Гипертензия}

Артериальное давление+(АД) в состоянии покоя > 140/90 мм рт. ст. как минимум при двух измере

Возраст > 75 лет

Сахарный диабет

Гликемия натощак > 125- мг/дл (7 ммоль/л) либо прием пероральных сахароснижающих препара

Ранее перенесенный иняедьт, ТИА или эпизод тромбоэмболии

Сосудистые заболевания

Ранее перенесенный инфаркт миокарда, заболевания периферических артерий или бляшки в аб

Возраст 65-74 лет

Пол (женский)

\begin{tabular}{|l|}
+1 \\
\hline+1 \\
\hline
\end{tabular}

Введение шкалы CHA2DS2-VASc (таблица 3) упростило первоначальное решение по применению оральных антикоагулянтов (ОАК) у пациентов с аритмиями. С момента первого включения в руководящие принципы ESC в 2010 году, эта шкала широко используется в редакции последних рекомендаций. Как правило, пациентам без клинических фракторов риска инсульта не нужна антитромботическая терапия, в то время как пациенты с фракторами риска инсульта (то есть CHA2DS2-VASc = 1 балл или больше для мужчин и 2 балла или больше для женщин) могут извлечь выгоду из 
применения ОАК (таблица 4).

Показатели развития инсульта и тромбоэмболий значительно отличаются у больных с CHA2DS2-VASc = 1 или 2 балла. Однако терапия OAK у мужчин с CHA2DS2-VASc c 1 баллом и женщин с 2 баллами предотвращает развитие инсультов, риск кровотечения и должна учитывать предпочтения пациента.

Важно отметить, что возраст (65 лет и старше) связан со сравнительно высоким и постоянно растущим риском инсульта, что также потенцирует и другие фракторы риска (например, сердечная недостаточность и пол). Таким образом, индивидуальное взвешивание риска, а также предпочтения пациента должны помочь в решении антикоагуляции пациентам с только одним фактором риска по CHA2DS2-VASc, помимо женского пола. Женский пол, сам по себе, не повышает риск инсульта при отсутствии других фракторов риска.

\section{Таблица 4. Современные рекомендации по назначению антикоагулянтной терапии в профиилактике инсультов у пациентов с ФП}

\section{Рекомендация}

\section{Класс рекомендации Уровень доказательности}

Терапия ОАК с целью профилактики тромбоэмёолии рекомендуется всем пациентам мужског Терапия ОАК с целью профилактики тромбоэмАолии рекомендуется всем пациентам, страдан Следует рассмотреть цевесообразность провеВения пероральной антикоагулянтной терапии Оценить целесообразнфқать проведения перорањьной АКТ у всех пациенток, страдающих ФП, Терапия ABK (MHO $\geq$ 2,0-3,0) рекомендуется двя профилактики инсульта у пациентов, страд При инициации терапии ОАК у пациента с ФП, Аоторому могут быть назначены НОАК (апикса Период в терапевтическом диапазоне (ПТД) у Аациентов, получающих АВК, должен быть мак Следует рассмотреть цеاbесообразность назнаћения НОАК пациентам, получающим АВК, есл Комбинация ОАК с ингибіи(вфами тромбоцитов Ввеличивает риск кровотечения; ее следует из

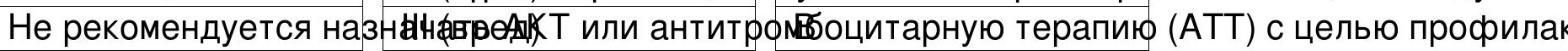
Монотерапия антитромбіф(врар))ыми средствамы не рекомендуется для профилактики инсуль НОАК (апиксабан, дабин由(ваєдыдоксабан, ривароксабан) не рекомендцется назначать пацие

Примечание. АВК - антагонисты витамина К, MHO - международное нормализованное отношение. 
Принципиальными являются следующие моменты:

- аспирин не следует использовать для профилактики тромбоэмболических осложнений у пациентов с ФП;

- пациентам со значением индекса CHA2DS2-VASc 1 балл для мужчин и 2 балла для женщин следует рассмотреть назначение антикоагулянтов (не аспирина);

- у пациентов с неклапанной ФП препаратами первого ряда являются «новые» пероральные антикоагулянты.

Согласно современным принципам антикоагулянтной терапии (таблица 4):

1. Прием антикоагулянтов с целью профилактики тромбоэмболических осложнений показан пациентам с ФП и индексом CHA2DS2-VASc 2 балла и более для мужчин, 3 балла и более для женщин (класс I A).

2. У мужчин со значением индекса CHA2DS2-VASc 1 и у женщин со значением индекса CHA2DS2-VASc 2 возможно назначение антикоагулянтов после оценки индивидуальных характеристик пациента и его предпочтений (класс Ila B).

3. Прием ОАК (оральные антикоагулянты - неантагонисты витамина К) (апиксабан, дабигатран, ривароксабан, эдоксабан) предпочтительнее, чем ABK, когда антикоагулянтная терапия впервые назначается пациентам с ФП (класс I A).

4. У принимающих АВК время пребывания МНО в целевом диапазоне должно тщательно контролироваться, следует стремиться к его максимальным значениям (класс I А). 
5. Если пациент уже принимает АВК, перейти на прием ОАК можно в том случае, если время пребывания МНО в целевом диапазоне неудовлетворительное, несмотря на хорошую приверженность к терапии, либо ориентируясь на предпочтения самого пациента (если нет противопоказаний, например, искусственных протезов клапанов сердца) (класс Ilb A).

Процедуре окклюзии или изоляции ушка левого предсердия в новых рекомендациях уделяется особое место:

- хирургическая изоляция или окклюзия ушка левого предсердия (ЛП) может быть выполнена во время вмешательства на открытом сердце у пациента с ФП (класс Ilb B);

- хирургическая изоляция или окклюзия ушка ЛП может быть выполнена во время торакоскопического вмешательства по поводу ФП (класc Ilb B). В случае неполной изоляции ушка ЛП и наличия остаточного кровотока риск инсульта может увеличиваться, поэтому:

- после выполнения хирургической изоляции или окклюзии ушка ЛП пациенту с ФП и высоким риском инсульта следует продолжать прием антикоагулянтов (класс I В);

- окклюзия ушка ЛП с целью профилактики инсульта может быть выполнена у пациента с противопоказаниями к длительной антикоагулянтной терапии (например, в анамнезе жизнеугрожающее кровотечение с неустранимой причиной) (класc Ilb B).

Выбор антитромботических препаратов является важным этапом лечения ФП (рисунок 2). 

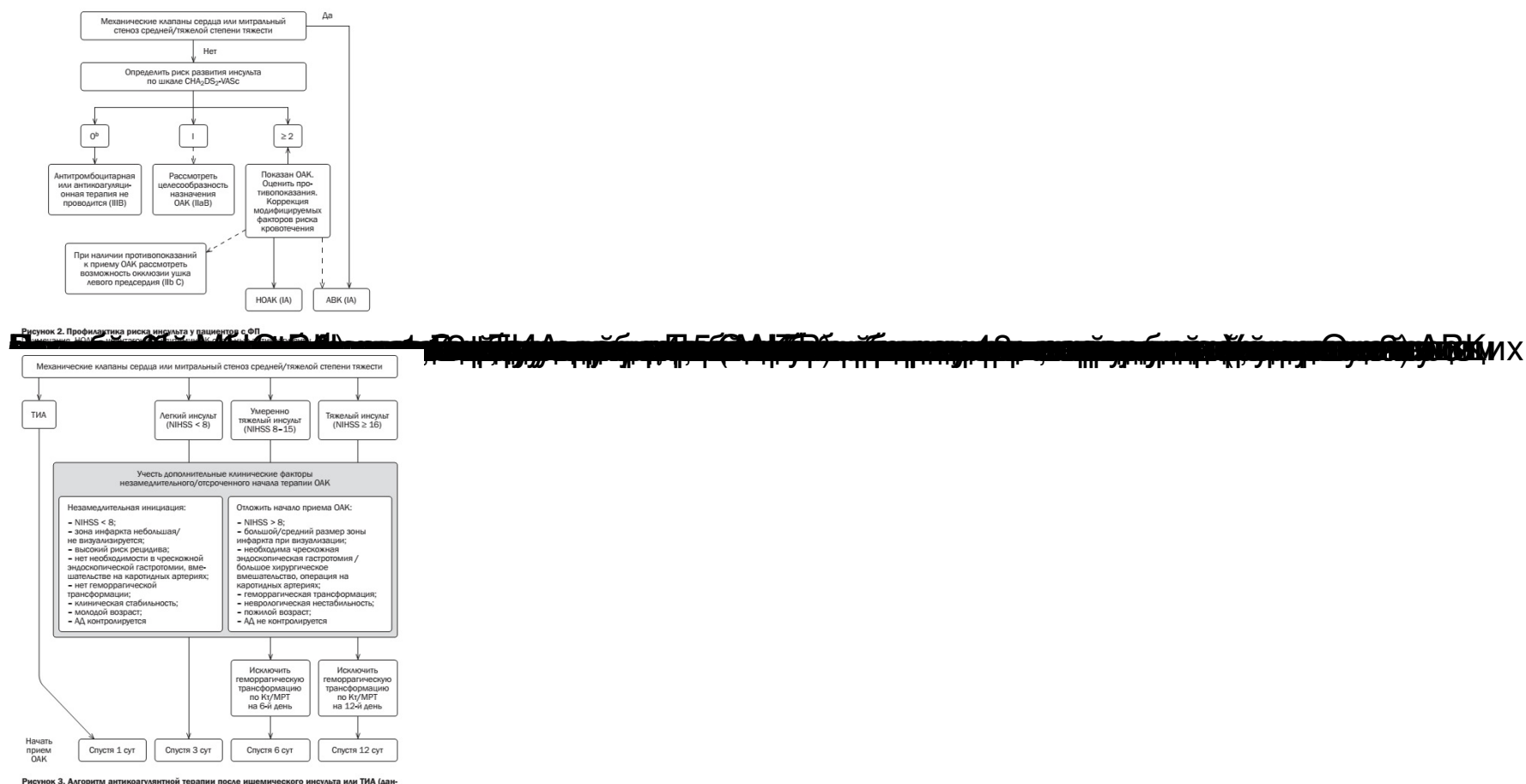

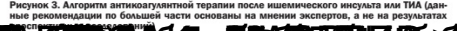

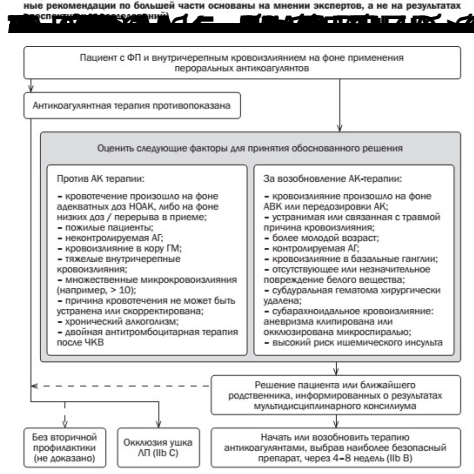

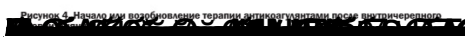
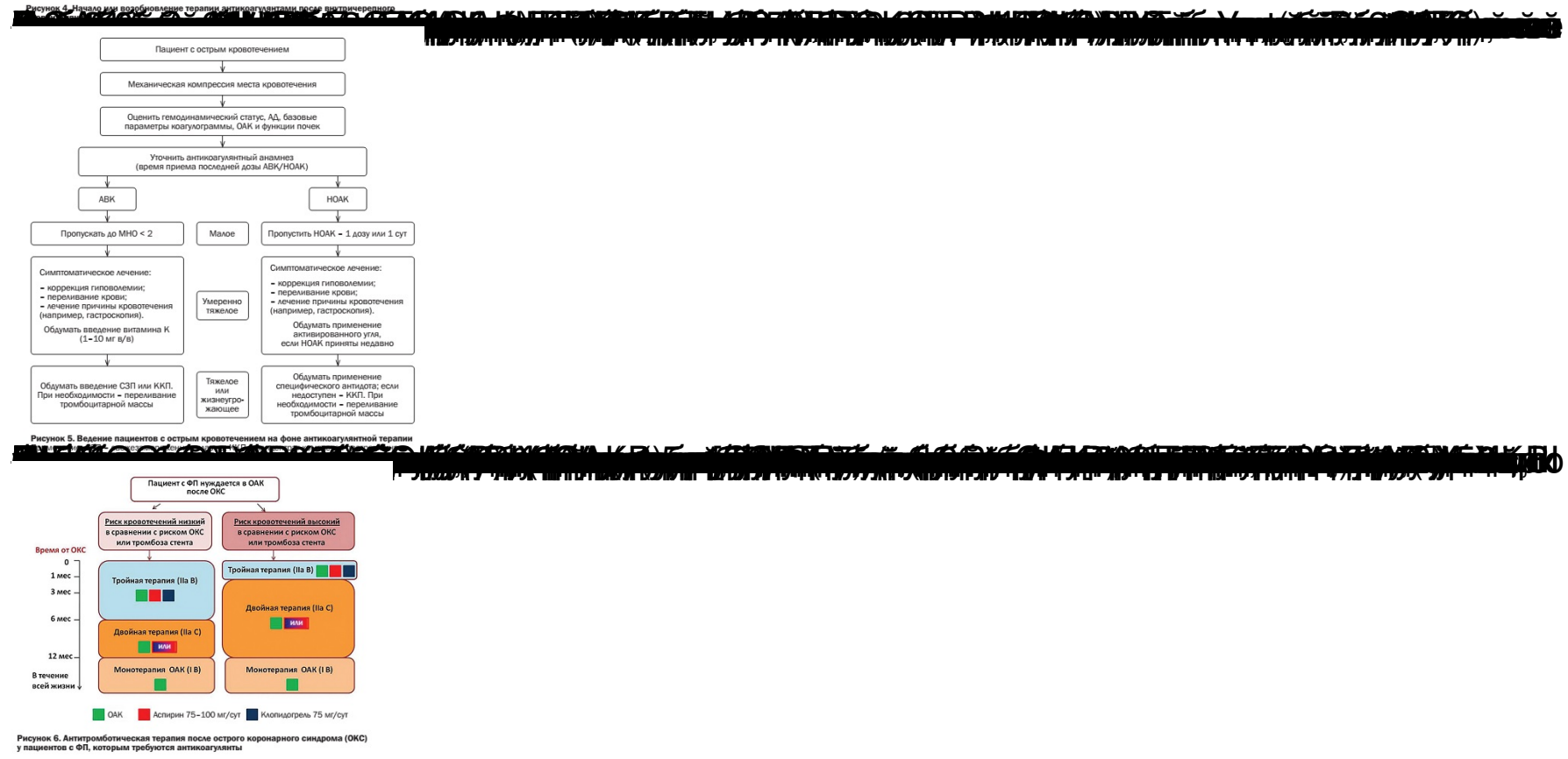

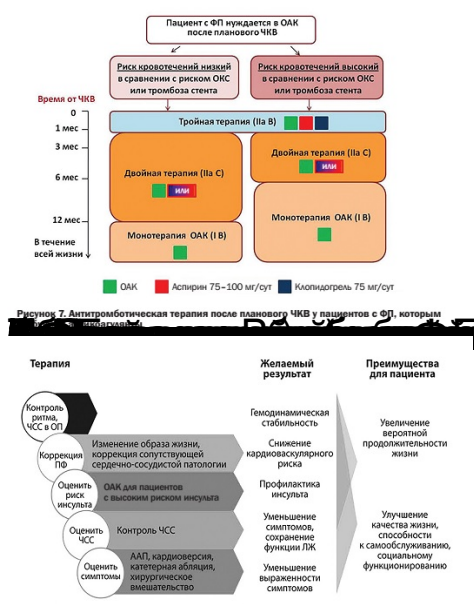